University of Nebraska - Lincoln

DigitalCommons@University of Nebraska - Lincoln

Agronomy \& Horticulture -- Faculty Publications

Agronomy and Horticulture Department

July 2004

\title{
Nitrogen Mineralization from Humic Acid Fractions in Rice Soils Depends on Degree of Humification
}

\author{
Bao Ve Nguyen \\ Can Tho Univ., CanTho, Vietnam \\ D. C. Olk \\ USDA-ARS
}

Kenneth G. Cassman

University of Nebraska-Lincoln, kcassman1@unl.edu

Follow this and additional works at: https://digitalcommons.unl.edu/agronomyfacpub

Part of the Plant Sciences Commons

Nguyen, Bao Ve; Olk, D. C.; and Cassman, Kenneth G., "Nitrogen Mineralization from Humic Acid Fractions in Rice Soils Depends on Degree of Humification" (2004). Agronomy \& Horticulture -- Faculty Publications. 108.

https://digitalcommons.unl.edu/agronomyfacpub/108

This Article is brought to you for free and open access by the Agronomy and Horticulture Department at DigitalCommons@University of Nebraska - Lincoln. It has been accepted for inclusion in Agronomy \& Horticulture -Faculty Publications by an authorized administrator of DigitalCommons@University of Nebraska - Lincoln. 


\title{
Nitrogen Mineralization from Humic Acid Fractions in Rice Soils Depends on Degree of Humification
}

\author{
Nguyen Bao Ve, D. C. Olk,* and K. G. Cassman
}

\begin{abstract}
Although the chemical nature of soil organic matter (SOM) is thought to affect the mineralization rate of $\mathrm{N}$ bound in SOM, little direct evidence exists for such effects. To test the hypothesis that the $\mathrm{N}$ mineralization rate is affected by the degree of SOM humification, we added equivalent amounts of humic acid (HA) $N$ as either the labile mobile humic acid (MHA) fraction or the more humified calcium humate (CaHA) fraction to two lowland rice (Oryza sativa $\mathbf{L}$.) soils, which were subsequently incubated under anaerobic conditions for $6 \mathrm{wk}$. The HA fractions had been chemically extracted from seven irrigated lowland rice soils from Vietnam and the Philippines. In both incubation soils, the amount of $\mathrm{N}$ mineralized from the added $\mathrm{HA}$ fractions decreased exponentially as the optical density of the HA at $465 \mathrm{~nm}\left(E_{4}\right.$, index of humification) increased $\left(R^{2}=0.94-0.98\right)$. Mineralization of humic $\mathbf{N}$ was also strongly negatively associated with the amount of $\mathbf{N}$ or $\mathbf{C}$ contained in each $\mathrm{HA}$ fraction per kilogram of soil extracted, suggesting a more recalcitrant nature of the fractions in those soils where conditions allowed them to accumulate. Nitrogen mineralization was less for both the MHA (by 26\%) and CaHA (by 41\%) when incubated in the International Rice Research Institute (IRRI) soil compared with the Tanhoi soil. The most plausible explanation for this decrease is increased stabilization of the added $\mathrm{HA}$ by the relatively abundant $\mathrm{Ca}^{+2}$ in the IRRI soil. We conclude that the degree of humification of the MHA and CaHA fractions plays an important role in governing the rate of $\mathrm{N}$ mineralization in lowland rice soils because (i) $\mathrm{N}$ mineralization from these fractions was affected by their degree of humification, and (ii) the fractions are a small but important component of total soil $\mathbf{N}$.
\end{abstract}

$\mathrm{M}$ ANAGEMENT OF INDIGENOUS SOIL $\mathrm{N}$ is an important issue in irrigated lowland rice systems because $\mathrm{N}$ mineralization from SOM provides a substantial portion of the total $\mathrm{N}$ taken up by a rice crop. In a companion paper (Nguyen et al., 2004), we used stepwise regression to predict parameters of net $\mathrm{N}$ mineralization from anaerobic incubation of 12 lowland rice soils. The prediction was improved when the independent variables of the regression included not only whole soil properties, such as total soil N, but also the properties and amounts of specific HA fractions in each soil. These results point to the relevance of chemically extracted HA fractions to achieving better understanding of process-level controls on soil $\mathrm{N}$ mineralization in lowland rice.

Although the chemical nature of SOM is thought to affect the mineralization rate of SOM-bound N (Stevenson and Cole, 1999), little direct evidence exists for

B.V. Nguyen, Dep. of Crop Sciences, Can Tho Univ., Can Tho, Vietnam; D.C. Olk, USDA-ARS, National Soil Tilth Laboratory, 2150 Pammel Dr., Ames, IA 50011; and K.G. Cassman, Dep. of Agronomy and Horticulture, Univ. of Nebraska, Lincoln, NE 68583-0915. Journal Series No. 14403 from the Agricultural Research Division, Univ. of Nebraska. Received 22 Nov. 2003. *Corresponding author (olk@nstl.gov).

Published in Soil Sci. Soc. Am. J. 68:1278-1284 (2004).

(c) Soil Science Society of America

677 S. Segoe Rd., Madison, WI 53711 USA such effects, especially for chemically extracted SOM fractions. In this study, we explore the relationship between the chemical nature of extracted HA fractions and their pattern of $\mathrm{N}$ mineralization when the fractions were added to two test soils and incubated. The same two fractions were examined as were used by Nguyen et al. (2004) to study soil $\mathrm{N}$ mineralization in lowland rice: (i) the MHA, which is a young HA fraction that is relatively $\mathrm{N}$-rich and can be extracted from soil without prior removal of polyvalent cations, and the CaHA fraction, which is somewhat older than the MHA and stabilized by polyvalent cations (Olk et al., 1995, 1996).

The primary objective of these experiments was to test the hypothesis that the rate of $\mathrm{N}$ mineralization from these HA fractions was influenced by their degree of humification, which varies due to soil management practices and the environmental conditions in these lowland rice fields (Olk et al., 1996, 1998; Mahieu et al., 2002; Nguyen et al., 2004). A secondary objective was to determine whether $\mathrm{N}$ mineralization from these fractions was related to other chemical properties of these fractions or properties of the soils from which the fractions were extracted.

\section{MATERIALS AND METHODS}

\section{Selection of Soils}

The MHA and CaHA were extracted from seven of the 14 lowland rice soils used by Nguyen et al. (2004). To ensure a representative subset of the 14 soils, we hypothesized that potential $\mathrm{N}$ mineralization of the humic fractions was related to the MHA-N fraction, which is the ratio of the amount of $\mathrm{N}$ contained in the MHA per kilogram of extracted soil (MHA-N) to the sum of MHA-N and CaHA-N. This hypothesis was based on the interpretation by Nguyen et al. (2004) and Olk et al. (1998) that in the better-aerated, low-N soils (such as the Guimba and Philippine Rice Institute [PhilRice] soils), young humic materials such as the MHA are more readily decomposed than in soils that remain under anoxic conditions for most of the year, resulting in accumulation of a more recalcitrant form of young humic materials in the anoxic soils. Thus, the 14 soils were grouped by their MHA-N fraction and two to three soils were selected from each of three groups: (i) MHA-N fraction $<0.50$, (ii) MHA-N fraction $\approx 0.50$, and (iii) MHA-N fraction $>0.50$. Of the seven selected soils, Guimba is from a farmer's field in Central Luzon, Philippines, PhilRice is from the Long-Term Fertility Experiment (LTFE) at the Philippine Rice Research Institute in Central Luzon, IRRI is from the LTFE at the International Rice Research Institute in Luzon, Cuulong is from a long-term experiment in the Mekong Delta of Vietnam, and Cantho, Huongso, and Tanhoi are from farmers' fields in the Mekong Delta and

Abbreviations: $\mathrm{CaHA}$, calcium humates; $\mathrm{E}_{4}$, optical density at 465 nm; HA, humic acid; IRRI, International Rice Research Institute; LTFE, Long-term Fertility Experiment; MHA, mobile humic acids; PhilRice, Philippine Rice Research Institute; SOM, soil organic matter. 
Table 1. Tropical lowland rice soils used for extraction of the humic acid fractions. $\dagger$

\begin{tabular}{|c|c|c|c|c|c|c|c|c|c|c|}
\hline \multirow[b]{2}{*}{ Soil } & \multirow{2}{*}{$\underset{\text { organic C }}{\text { Soil }}$} & \multirow{2}{*}{$\begin{array}{l}\text { Total } \\
\text { soil N }\end{array}$} & \multirow[b]{2}{*}{ pH } & \multirow[b]{2}{*}{ Clay } & \multirow[b]{2}{*}{ Silt } & \multirow[b]{2}{*}{ CEC } & \multicolumn{4}{|c|}{$1 M$ ammonium acetate-extractable cations } \\
\hline & & & & & & & $\mathbf{C a}$ & Mg & $\mathbf{K}$ & $\mathbf{N a}$ \\
\hline & \multicolumn{2}{|c|}{$\mathrm{g} \mathrm{kg}^{-1}$ soil } & & \multicolumn{2}{|c|}{$-\mathrm{g} \mathrm{kg}^{-1}$ soil - } & & & $-\mathbf{c m}$ & soil - & - \\
\hline Guimba & 12.1 & 1.00 & 7.7 & 360 & 430 & 27.1 & 18.8 & 12.3 & 0.10 & 0.56 \\
\hline PhilRice & 15.5 & 1.25 & 6.6 & 400 & 505 & 25.4 & 18.0 & 8.4 & $\mathbf{0 . 1 1}$ & 0.56 \\
\hline Tanhoi§ & 21.2 & 2.09 & 6.0 & 680 & 300 & 22.6 & 10.8 & 10.7 & 0.36 & 1.13 \\
\hline Cuulong & 32.6 & 2.96 & 5.5 & 560 & 436 & 22.0 & 11.1 & 8.1 & 0.23 & 0.48 \\
\hline IRRI§ & 22.0 & 1.84 & 6.5 & $\mathbf{5 5 0}$ & 355 & 35.7 & 18.2 & 11.8 & 1.51 & 1.44 \\
\hline Cantho & 26.4 & 2.34 & 5.3 & 445 & 545 & 15.9 & 9.3 & 2.8 & 0.24 & 0.28 \\
\hline Huangso & 14.1 & 1.36 & 6.3 & 200 & 530 & 4.2 & 2.3 & 1.5 & 0.09 & 0.50 \\
\hline
\end{tabular}

† Data are from Nguyen et al. (2004), who also reported the analyses used to obtain the data.

+ Cation-exchange capacity.

§ Also used as an incubation soil.

Hue region of central Vietnam. These soils have a wide range of organic $\mathrm{C}$, total $\mathrm{N}$, and other soil chemical and physical properties (Table 1 ).

The MHA and CaHA fractions that were extracted from these seven "extraction soils" were added separately to the IRRI and Tanhoi soils to determine their $\mathrm{N}$ mineralization patterns during anaerobic incubations. These two "incubation soils" were selected because they had near neutral $\mathrm{pH}$ and low K-fixing capacity, which are properties conducive for amendment with HA and measurement of subsequent $\mathrm{N}$ mineralization. Both incubation soils had soil organic $\mathrm{C}$ of about $20 \mathrm{~g} \mathrm{~kg}^{-1}$, total soil $\mathrm{N}$ of about $2 \mathrm{~g} \mathrm{~kg}^{-1}$, and high clay contents (Table 1). The IRRI soil had a higher cation-exchange capacity than the Tanhoi soil due to a higher exchangeable Ca content (Table 1). For each incubation soil a composite soil was made from field replicates and used for all mineralization incubations.

\section{Extraction and Characterization of MHA and CaHA fractions}

The MHA and CaHA were extracted from three field replicates of each soil as described by Nguyen et al. (2004), following the procedure of Olk et al. (1996). Briefly, $18 \mathrm{~g}$ of airdried soil was incubated in $180 \mathrm{~mL}$ of $0.25 M \mathrm{NaOH}$ for $20 \mathrm{~h}$ and then centrifuged. The supernatant was decanted and acidified to $\mathrm{pH} 1.95$ to precipitate the MHA. The soil residue was washed twice with $0.0025 \mathrm{M} \mathrm{CaCl}_{2}$ to remove fine clays in suspension that had combined with soluble MHA, then decalcified by repeated $0.1 \mathrm{M} \mathrm{HCl}$ washes. The CaHA was subsequently extracted from the soil with $0.25 \mathrm{M} \mathrm{NaOH}$ using the same protocol as for the MHA. To reduce inorganic contamination, both the MHA and CaHA were shaken in an $\mathrm{HF} / \mathrm{HCl}$ solution for $3 \mathrm{~d}$ with daily solution replacement. The MHA and CaHA were $\mathrm{H}^{+}$-saturated by dialyzing for $3 \mathrm{~d}$ against $\mathrm{HCl}$ solutions and water. Then the MHA and $\mathrm{CaHA}$ were frozen, lyophilized, and stored as a dry powder.

The $\mathrm{C}$ and $\mathrm{N}$ concentrations of the MHA and CaHA were determined by dry combustion on a CHN automated elemental analyzer. Per kilogram of extracted soil, the amounts of $\mathrm{N}$ or $\mathrm{C}$ contained in the extracted MHA (MHA-N or MHA-C) and CaHA (CaHA-N or CaHA-C) were estimated as the products of the $\mathrm{N}$ and $\mathrm{C}$ concentrations of each $\mathrm{HA}$ fraction and their mass extracted per kilogram of extracted soil. Optical density at $465 \mathrm{~nm}$ was determined on solutions of $3 \mathrm{mg}$ HA-C solubilized in $30 \mathrm{~mL}$ of $0.05 \mathrm{M} \mathrm{NaHCO}_{3}$ (Chen et al., 1977). Ash content was determined gravimetrically after heating to $700^{\circ} \mathrm{C}$ for $3 \mathrm{~h}$. All values reported for $\mathrm{C}$ and $\mathrm{N}$ concentration are corrected for ash content.

\section{Humic Acid Addition and In Vitro Soil Nitrogen Mineralization Procedure}

Because the HA fractions were $\mathrm{H}^{+}$-saturated during their extraction from soil, their addition to the IRRI and Tanhoi soils could cause soil acidification. Hence before their addition to the IRRI and Tanhoi soils, the extracted MHA and CaHA fractions were saturated with $\mathrm{K}^{+}$by solubilizing HA containing $100 \mathrm{mg} \mathrm{N}$ in $10 \mathrm{~mL}$ of $0.05 \mathrm{M} \mathrm{KOH}$ in a beaker with constant mixing by a magnetic stirrer. After solubilization, the $\mathrm{HA}$ solution was adjusted to $\mathrm{pH} 7$ with dilute $\mathrm{HCl}$, then frozen, lyophilized, ground, and stored as a dry powder. Nitrogen concentrations of the $\mathrm{K}^{+}$-saturated $\mathrm{HA}$ samples were measured again to estimate the addition rate of each HA sample to the incubation soils based on an equivalent $\mathrm{N}$ addition level of $200 \mathrm{mg} \mathrm{N} \mathrm{kg}^{-1}$ incubation soil. This rate was selected to represent the increase in total soil $\mathrm{N}$ that can occur under field conditions following the introduction of double- or triplecropping of irrigated lowland rice (Cassman et al., 1995; Witt et al., 2000). The mass of HA $\left(\mathrm{K}^{+}-\right.$free basis $)$that was added to the incubation soils ranged from 3.48 to $4.26 \mathrm{~g} \mathrm{MHA} \mathrm{kg}^{-1}$ incubation soil and from 3.89 to $5.60 \mathrm{~g} \mathrm{CaHA} \mathrm{kg}^{-1}$ soil.

Quantities of each MHA and CaHA fraction corresponding to $0.4 \mathrm{mg} \mathrm{N}$ were mixed into $2 \mathrm{~g}$ of dry soil in 20 -mL glass test tubes with three replications. These tubes were stored in an incubator overnight at $10^{\circ} \mathrm{C}$. The next day each tube received $1 \mathrm{~mL}$ of cold $\left(10^{\circ} \mathrm{C}\right)$ water and was flushed with $\mathrm{N}_{2}+$ $5 \%(\mathrm{v} / \mathrm{v}) \mathrm{CO}_{2}$ gas for $20 \mathrm{~s}$ at a flow rate of $2.5 \mathrm{~mL} \mathrm{~s}^{-1}$. Tubes were stoppered immediately and placed in an incubator for $2 \mathrm{~d}$ at $10^{\circ} \mathrm{C}$ to allow chemical equilibration between $\mathrm{HA}$ and soil. After $2 \mathrm{~d}, 1 \mathrm{~g}$ of dry $\mathrm{K}^{+}$-saturated resin was added to each tube followed by $14 \mathrm{~mL}$ of deionized water. Resin was kept on the surface of the soil to avoid interactions between the amended HA and resin. The tubes were flushed with $\mathrm{N}_{2}+5 \% \mathrm{CO}_{2}$ gas and stoppered as above, then placed in an incubator at $30^{\circ} \mathrm{C}$.

The triplicate tubes of each soil and MHA or CaHA combination were extracted for mineralized $\mathrm{NH}_{4}$ at 0,21 , and $42 \mathrm{~d}$ after resin addition, following the procedure described by Nguyen et al. (2004). Briefly, at sampling time the contents of each tube were transferred to a $50-\mathrm{mL}$ centrifuge tube via three 5-mL washes of $4 \mathrm{M} \mathrm{KCl}$. This solution was shaken and centrifuged. The supernatant was filtered and acidified before storage. Soil was extracted again with $\mathrm{KCl}$ to recover residual $\mathrm{NH}_{4}$. The $\mathrm{NH}_{4}-\mathrm{N}$ concentration in each extract was determined spectrophotometrically (Kempers and Zweers, 1986) and summed for both soil washes. As a control, triplicate tubes containing soil without HA addition were also extracted at each sampling time for both incubation soils. Extractable $\mathrm{NH}_{4}$ in the control samples was subtracted from extractable $\mathrm{NH}_{4}$ in the HA-amended samples to determine the amount of $\mathrm{N}$ mineralized from the added HA.

\section{Statistical Analysis}

The relationship between $\mathrm{N}$ mineralization of $\mathrm{HA}$ fractions added to the IRRI incubation soil and $\mathrm{N}$ mineralization of HA fractions added to the Tanhoi incubation soil was evaluated by 
Table 2. Selected properties of the mobile humic acid (MHA) and calcium humate (CaHA) fractions extracted from seven tropical lowland rice soils for addition to two incubation soils. $\dagger$

\begin{tabular}{|c|c|c|c|c|c|c|c|c|c|c|c|c|c|}
\hline \multirow[b]{2}{*}{ Soil } & \multirow{2}{*}{$\begin{array}{c}\text { MHA } \\
\text { fraction }\end{array}$} & \multicolumn{2}{|c|}{$\mathbf{N}$ content } & \multicolumn{2}{|c|}{ C content } & \multicolumn{2}{|c|}{$\mathbf{N}$ concentration } & \multicolumn{2}{|c|}{$\mathrm{C}$ concentration } & \multicolumn{2}{|c|}{$\mathrm{C} / \mathrm{N}$ ratio } & \multicolumn{2}{|c|}{$\mathbf{E}_{4} \doteqdot$} \\
\hline & & МHА & CaHA & МНА & CaHA & МHА & CaHA & МHA & CaHA & МНА & CaHA & МHА & CaHA \\
\hline & & & $\mathrm{g} \mathrm{kg}^{-1}$ ex & ction so & 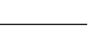 & & $\mathrm{g} \mathrm{kg}^{-1}$ & nic acid & & & & & \\
\hline Guimba & 0.15 & 0.022 & 0.130 & 0.21 & 2.14 & 57.5 & 35.7 & 538 & 575 & 9.4 & 16.1 & 2.05 & 13.3 \\
\hline PhilRice & 0.37 & 0.074 & 0.124 & 0.76 & 1.87 & 53.3 & 37.3 & 541 & 554 & 10.2 & 14.9 & 2.24 & 10.0 \\
\hline Tanhoi & 0.52 & 0.178 & 0.167 & 1.79 & 2.14 & 53.7 & 43.7 & 540 & 554 & 10.0 & 12.7 & 3.62 & 10.7 \\
\hline Cuulong & 0.52 & 0.464 & 0.432 & 4.90 & 5.02 & 52.1 & 51.4 & 542 & 573 & 10.4 & 11.2 & 7.77 & 16.6 \\
\hline IRRI & 0.58 & 0.213 & 0.155 & 2.41 & 2.18 & 47.0 & 40.0 & 539 & 552 & 11.5 & 13.8 & 3.58 & 9.8 \\
\hline Cantho & 0.71 & 0.451 & 0.184 & 5.00 & 2.45 & 49.8 & 42.8 & 546 & 564 & 11.0 & 13.2 & 5.21 & 11.0 \\
\hline Huongso & 0.71 & 0.212 & 0.085 & 2.15 & 0.99 & 54.2 & 48.6 & 526 & 529 & 9.7 & 10.9 & 3.36 & 8.1 \\
\hline
\end{tabular}

† Data are from Nguyen et al. (2004), who also reported the analyses used to obtain the data.

+ Optical density at $465 \mathrm{~nm}$. Units are optical density units $\left(\mathrm{g} \text { HA-C } \mathrm{L}^{-1}\right)^{-1}$.

correlation analysis. Relationships between the amount of $\mathrm{N}$ mineralized from the added HA fractions and specific chemical properties of the HA fractions or of the extraction soils were evaluated by regression analysis. Curvilinear relationships were identified using the TableCurve 2D software package, Version 4.0 (SPSS Inc., Chicago, IL). This software evaluates a family of curvilinear functions and identifies the model with the smallest residual sum of squares. Stepwise regression (SAS Institute, 1990) was used to determine which properties of whole soil significantly influenced the cumulative $\mathrm{N}$ mineralized from the HA fractions after 3 and $6 \mathrm{wk}$. Independent variables entered the model at a significance level of 0.15 .

\section{RESULTS}

\section{Nitrogen Mineralization of the MHA and CaHA}

The proportion of extracted HA N that was contained in the MHA, the MHA-N fraction, was $<40 \%$ for both the Guimba and PhilRice soils (Table 2). In contrast, the other five extraction soils had an MHA-N fraction ranging from 52 to $71 \%$. The MHA of the Guimba and PhilRice soils also had the smallest $\mathrm{E}_{4}$ values, and the Guimba soil had the highest $\mathrm{N}$ concentration of the MHA. After a 6-wk incubation in both incubation soils, the amount of $\mathrm{N}$ mineralized per unit $\mathrm{N}$ added as MHA was on average 18 to $116 \%$ greater for MHA extracted from the Guimba and PhilRice soils than for MHA extracted from the other soils (Table 3 ). Nitrogen mineralization from extracted CaHA did not differ in a consistent pattern between extraction soils with small or large MHA-N fractions.

After a 6-wk incubation, cumulative $\mathrm{N}$ mineralized was two to five times greater per unit $\mathrm{N}$ added as MHA than per unit $\mathrm{N}$ added as $\mathrm{CaHA}$, and most of this difference occurred during the first 3 wk of incubation (Table 3). For example, after a 3-wk incubation in the IRRI soil, $\mathrm{N}$ mineralized ranged from 111 to $230 \mathrm{~g}$ $\mathrm{NH}_{4}-\mathrm{N} \mathrm{kg}^{-1}$ MHA-bound $\mathrm{N}$ and from 17 to $43 \mathrm{~g} \mathrm{NH}_{4}-\mathrm{N}$ $\mathrm{kg}^{-1}$ CaHA-bound N. From 3 to $6 \mathrm{wk}$, cumulative N mineralized from added MHA and CaHA slowed dramatically, and the decrease was greater for the MHA. The coefficient of variation for $\mathrm{N}$ mineralization from the HA fractions across extraction soils was greater for MHA than for CaHA in both time periods. After $6 \mathrm{wk}$, cumulative $\mathrm{N}$ mineralization varied among extracted soils by 1.7- to 3.2-fold for the four combinations of HA fraction and incubation soil.

The relative pattern of cumulative $\mathrm{N}$ mineralized from HA was generally similar whether the HA was incubated in the Tanhoi soil or the IRRI soil. Thus, there was a close linear correlation between the quantity of $\mathrm{N}$ mineralization from $\mathrm{N}$ added as MHA to the IRRI soil and $\mathrm{N}$ mineralization from $\mathrm{N}$ added as MHA to the Tanhoi soil at both 3 (Fig. 1a) and 6 wk (Fig. 1b). In contrast, the relationship between $\mathrm{N}$ mineralization from $\mathrm{N}$ added as $\mathrm{CaHA}$ in the two incubation soils was more clustered. The quantities of $\mathrm{N}$ mineralized from both HA fractions were substantially less when incubated in the IRRI soil than in the Tanhoi soil. For example, after the 6-wk incubation, $\mathrm{N}$ mineralized from MHA added to the IRRI soil was on average $26 \%$ less than from MHA added to the Tanhoi soil; for CaHA, the decrease was $41 \%$ in the IRRI soil compared with the Tanhoi soil (Table 3).

Table 3. Nitrogen $\left(\mathrm{NH}_{4}-\mathrm{N}\right)$ mineralized from the mobile humic acid (MHA) and calcium humate (CaHA) fractions extracted from seven tropical lowland rice soils and added to the IRRI and Tanhoi soils for incubation under anaerobic conditions.

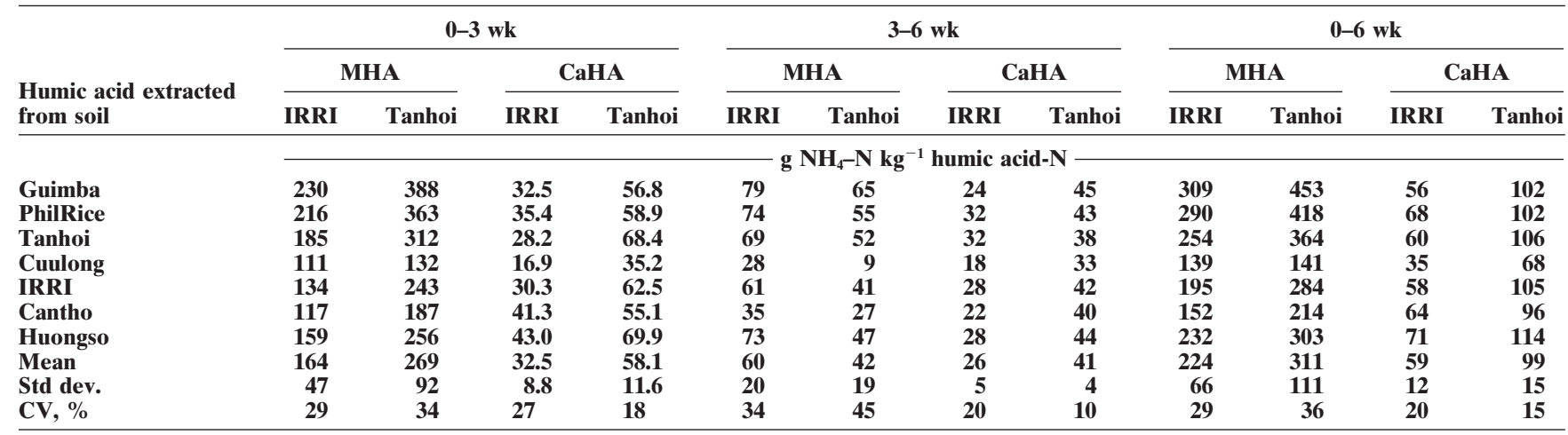



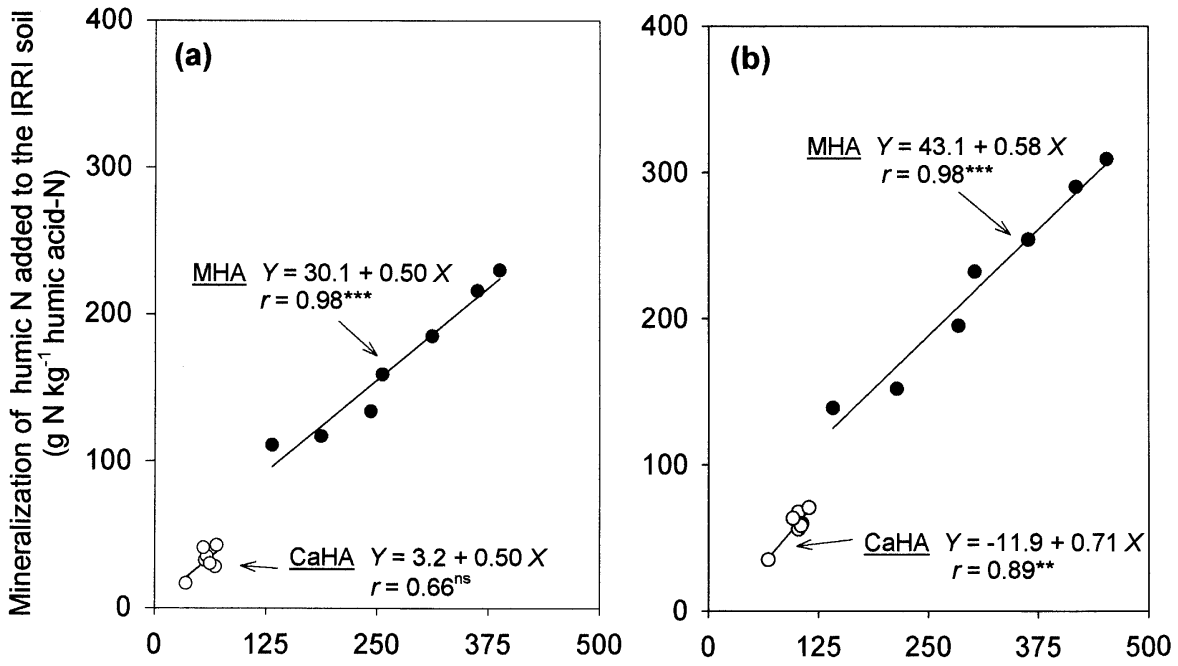

Mineralization of humic $\mathrm{N}$ added to the Tanhoi soil ( $\mathrm{g} \mathrm{N} \mathrm{kg}^{-1}$ humic acid- $\mathrm{N}$ )

Fig. 1. The correlation between the amount of $\mathbf{N}$ mineralized from the mobile humic acid (MHA) fraction or the calcium humate (CaHA) fraction that were extracted from seven tropical lowland rice soils and incubated in the IRRI soil versus Tanhoi soil under anaerobic conditions at $30^{\circ} \mathrm{C}$ for (a) 3 and (b) 6 wk. $* *$ and $* * *$ indicate significance at 1 and $0.1 \%$ levels, respectively; ns is not significant.

\section{Nitrogen Mineralization as Influenced by Chemical Properties of the Humic Acid Fractions}

Nitrogen mineralized from each HA fraction was negatively associated with the $\mathrm{HA} \mathrm{N}$, the amount of $\mathrm{N}$ contained in each humic fraction per kilogram of extraction soil, for Tanhoi (Fig. 2a) and IRRI (Fig. 2b) incubations. For the MHA, these relationships were best described by exponential equations of the form:

$$
Y=a+b \exp (-X / c)
$$

where $Y$ is the amount of $\mathrm{N}$ mineralized from the added MHA, $X$ is the MHA-N content per kilogram of extraction soil, and $a, b$, and $c$ are constants. Corresponding data for the CaHA fraction were best fit by a power function of the form:

$$
Y=a+b X^{c}
$$

where $Y$ is the amount of $\mathrm{N}$ mineralized from the added CaHA, $X$ is the CaHA-N content per kilogram of extraction soil, and $a, b$, and $c$ are constants. Fits were closer for the MHA than for the CaHA. The coefficients of determination between HA-C content per kilogram of extraction soil as the independent variables and mineralized $\mathrm{N}$ from added $\mathrm{HA}$ fractions as the dependent variables, were as high as when the independent variables were HA-N content per kilogram of extraction soil (data not shown). The degree of fit for these regressions was comparable in both incubation soils despite the smaller amount of $\mathrm{N}$ mineralization from humic $\mathrm{N}$ added to the IRRI soil.

The cumulative amounts of $\mathrm{N}$ mineralization at $6 \mathrm{wk}$ were pooled for both fractions and regressed against the $\mathrm{E}_{4}$ optical density values using the exponential model of Eq. [1]. The amounts of $\mathrm{N}$ mineralized from the MHA and CaHA were strongly negatively associated with the $E_{4}$ values (Fig. 3a,b). Nitrogen mineralization from the MHA fraction was also negatively associated with the $\mathrm{C} / \mathrm{N}$ ratio of the MHA, but the data were not significantly fit by linear, power, or exponential equations (data not shown). No trend was apparent between $\mathrm{N}$ mineralization from the CaHA fraction and the $\mathrm{C} / \mathrm{N}$ ratio of the CaHA.

Although $\mathrm{N}$ mineralization from the added MHA and $\mathrm{CaHA}$ was also significantly associated with soil organic $\mathrm{C}$ and total soil $\mathrm{N}$ of the extraction soils (Table 1), the coefficients of determination were much weaker than for the relationships shown in Fig. 2 and 3. For example, coefficients of determination for exponential relationships (Eq. [1]) with $\mathrm{N}$ mineralized from the MHA at either 3 or $6 \mathrm{wk}$ as the dependent variable ranged from 0.71 to 0.80 for soil organic $\mathrm{C}$ and from 0.73 to 0.78 for total soil N. Simple linear regressions with soil organic $\mathrm{C}$ or total soil $\mathrm{N}$ were slightly weaker than the exponential and power functions. Other properties of the extraction soils, including particle-size fractions and exchangeable cations, did not have significant linear relationships with $\mathrm{N}$ mineralized from the MHA and CaHA, except for positive associations of soil $\mathrm{pH}$ with MHA mineralization in both incubation soils and at both sampling times $\left(R^{2}=0.82-0.84\right)$.

Stepwise regression analysis using properties of the extracted soils as independent variables provided similar predictions of cumulative $\mathrm{N}$ mineralization as did the amount of $\mathrm{N}$ contained in the HA fraction per kilogram of extraction soil (Fig. 2) for (i) MHA incubated in the Tanhoi soil for $3 \mathrm{wk}$, (ii) MHA incubated in both soils for $6 \mathrm{wk}$, and (iii) CaHA incubated in the IRRI soil for $6 \mathrm{wk}$. In all three MHA cases, soil organic C and clay content were negatively and positively, respectively, associated with humic $\mathrm{N}$ mineralization, and soil organic $\mathrm{C}$ was the more important predictor. For all other incubation times of MHA and CaHA in either incubation soil, stepwise regression identified either soil organic $\mathrm{C}$ or clay content as the sole soil property that was significantly associated with cumulative $\mathrm{N}$ mineral- 

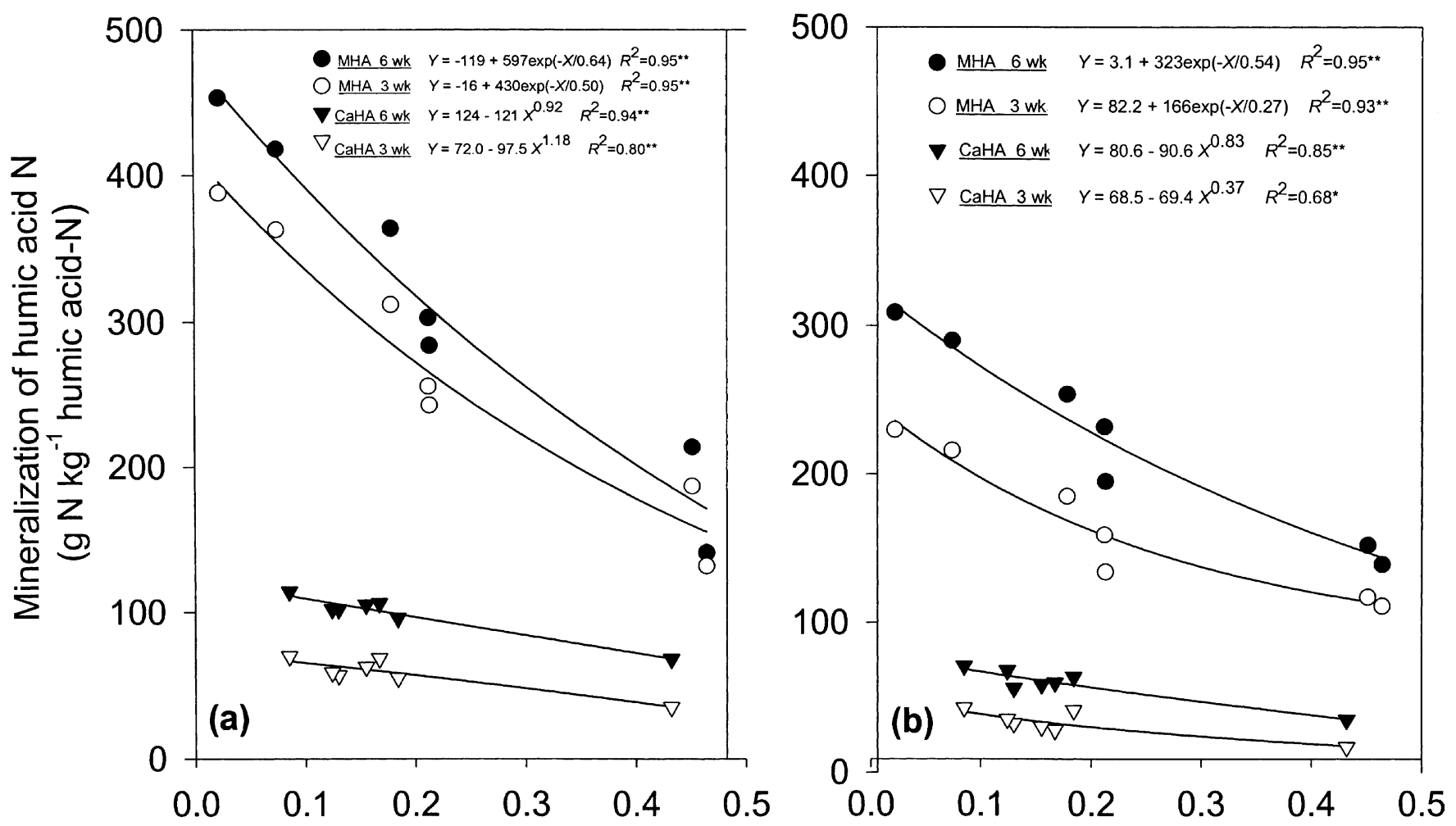

Amount of $\mathrm{N}$ in the humic acid fraction per $\mathrm{kg}$ extraction soil $\left(\mathrm{g} \mathrm{N} \mathrm{kg}^{-1}\right.$ soil)

Fig. 2. The relationship between the amount of humic acid $\mathbf{N}$ mineralized and the amount of $\mathbf{N}$ contained in the humic acid fraction per kg extraction soil for the mobile humic acid (MHA) fraction and the calcium humate (CaHA) fraction that were extracted from seven tropical lowland rice soils and incubated in the (a) Tanhoi and (b) IRRI soils under anaerobic conditions at $30^{\circ} \mathrm{C}$ for 3 and 6 wk. * and ** indicate significance at 5 and $1 \%$ levels, respectively.
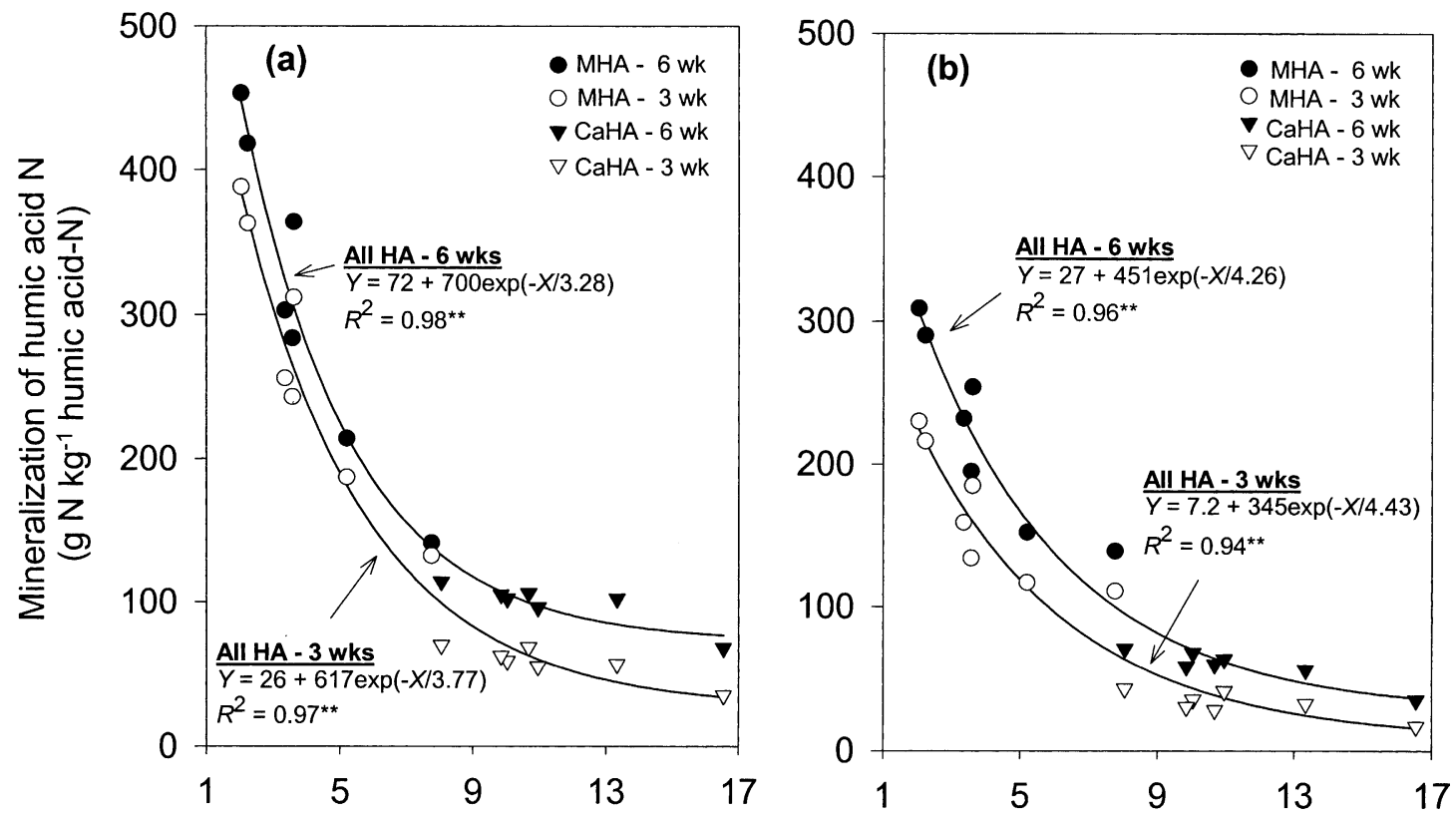

Optical density of HA at $465 \mathrm{~nm}$ (OD units $\left.\left(\mathrm{g} \mathrm{HA}-\mathrm{C} \mathrm{L}^{-1}\right)^{-1}\right)$

Fig. 3. The relationship between the amount of humic acid (HA) $\mathrm{N}$ mineralized and the optical density at $465 \mathrm{~nm}$ for the mobile humic acid (MHA) fraction and the calcium humate (CaHA) fraction that were extracted from seven tropical lowland rice soils and incubated in the (a) Tanhoi and (b) IRRI soils under anaerobic conditions at $30^{\circ} \mathrm{C}$ for 3 and 6 wk. ** indicates significance at $1 \%$ level. 
ization, and the coefficients of determination were considerably smaller than those of the humic acid $\mathrm{N}$ content per kilogram of extraction soil.

Nitrogen and C concentrations per unit of HA were significantly associated with $\mathrm{N}$ mineralized from the MHA or CaHA in only two cases: (i) the $\mathrm{N}$ concentration per unit of MHA (and hence also mass of MHA added) was positively associated with $\mathrm{N}$ mineralized from the MHA after a 3-wk incubation in the IRRI soil $\left(R^{2}=0.55, P<0.05\right)$, and (ii) the $\mathrm{C}$ concentration per unit of CaHA was negatively associated with $\mathrm{N}$ mineralized from the CaHA after a 3-wk incubation in the Tanhoi soil $\left(R^{2}=0.55, P<0.05\right)$.

\section{DISCUSSION}

Soil biochemical processes are assumed to influence the rate of $\mathrm{N}$ mineralization (Stevenson and Cole, 1999), yet direct evidence is sparse for process-level controls that apply across a range of environments. Likewise, $\mathrm{N}$ mineralization of specific SOM fractions has not been consistently related to their quantity or chemical composition other than their $\mathrm{C} / \mathrm{N}$ ratio, and most or all of this work has been based on physical separation of SOM fractions (Christensen, 1992; Feller and Beare, 1997; Whalen et al., 2000). In general, fundamental relationships between $\mathrm{N}$ cycling and biochemical properties of whole soil have not been established except for the inhibition of $\mathrm{N}$ mineralization by an abundance of phenolic compounds in coniferous forest soils, organic soils, and grassland soils (Burge and Broadbent, 1961; Schimel and Firestone, 1989; Bending and Read, 1996; Knicker et al., 2000).

In this study, $\mathrm{N}$ mineralization from the added MHA was greater than that from the added CaHA for each of the seven extraction soils and for incubations in both the IRRI and Tanhoi soils. This reproducibility suggests that the MHA is a distinctly more labile fraction than the CaHA in all soils. This finding is consistent with previous, more detailed studies of the chemical composition of these two HA fractions and speculation about their contributions to nutrient cycling (Mahieu et al., 2002; Olk and Cassman, 2002; Nguyen et al., 2004).

Nitrogen mineralization from the added HA fractions was closely related to the amounts of $\mathrm{N}$ and $\mathrm{C}$ contained in the HA fractions per kilogram of extraction soil and the $\mathrm{E}_{4}$ optical density value of the HA. These relationships were based on regressions that included two incubation soils and seven extraction soils with a wide range of chemical and physical properties, which indicates a reproducible relationship between humic acid chemistry and the mineralization potential of humic N. Most noteworthy were the strong negative associations of $\mathrm{N}$ mineralization with $\mathrm{E}_{4}$ (Fig. 3). Further, stepwise regressions by Nguyen et al. (2004) found that (i) the CaHA-E $\mathrm{E}_{4}$ was negatively associated with two rate constants for net $\mathrm{N}$ mineralization in these lowland rice soils, and (ii) the $\mathrm{E}_{4}$ values for both HA fractions were negatively associated with the size of a readily mineralizable $\mathrm{N}$ pool. An inverse relationship between $\mathrm{N}$ mineralization potential and the $\mathrm{E}_{4}$ value is consistent with the positive correla- tion of the $\mathrm{E}_{4}$ value with the degree of humification as determined by several spectroscopic analytical methods (Mahieu et al., 2002) and the greater recalcitrance of more humified humic materials to microbial decomposition (Zech et al., 1997; Stevenson and Cole, 1999). Yet $\mathrm{E}_{4}$ has not previously been linked to $\mathrm{N}$ mineralization, despite considerable work by Kumada (1987), Schnitzer and Lévesque (1979), and others that described optical density at visible light wavelengths as an index of humic lability.

The amount of $\mathrm{N}$ mineralized from either $\mathrm{HA}$ fraction was also negatively associated with the amount of $\mathrm{N}$ contained in that fraction per kilogram of extracted soil. Of the seven extraction soils, the MHA of three relatively anoxic soils, Cuulong, Cantho, and IRRI, had the largest $\mathrm{E}_{4}$ values and largest $\mathrm{N}$ contents per kilogram of extraction soil, yet the smallest amounts of $\mathrm{N}$ mineralization per unit N. Conversely, the MHA of two more aerated soils, Guimba and PhilRice, had the smallest $\mathrm{E}_{4}$ values and smallest $\mathrm{N}$ contents per kilogram of extraction soil yet the largest amounts of $\mathrm{N}$ mineralization per unit $\mathrm{N}$, indicating the sensitivity of the quantity and chemical composition of this SOM fraction to recent soil conditions.

Mineralization of HA-bound $\mathrm{N}$ was considerably less when the same HA fraction was incubated in the IRRI soil than in the Tanhoi soil. We attribute this difference to stronger stabilization of the added $\mathrm{HA}$ by $\mathrm{Ca}^{+2}$ in the IRRI soil, because this soil had $70 \%$ more extractable Ca than did the Tanhoi soil. Previous studies have demonstrated $\mathrm{Ca}$-induced stabilization of organic materials and SOM against microbial degradation (Baldock and Skjemstad, 2000; Kononova, 1961), and stepwise regressions by Nguyen et al. (2004) associated exchangeable $\mathrm{Ca}$ in these rice soils with formation or stabilization of SOM into the more recalcitrant CaHA fraction at the expense of the labile MHA fraction. In addition, the impedance of $\mathrm{N}$ mineralization from $\mathrm{HA}$ added to the IRRI soil compared with the Tanhoi soil was proportionately greater for the CaHA fraction ( $41 \%$ decrease) than for the MHA fraction (26\% decrease), suggesting that the polyvalent cation-bound CaHA was more amenable to stabilization by the IRRI soil than was the MHA. Based on this body of evidence, we propose that $\mathrm{Ca}$ was a primary agent for stabilization of the added HA, especially for the CaHA.

Calcium-induced stabilization of amended HA was further suggested by the results of an ancillary study in which $\mathrm{N}$ mineralization was measured during aerobic incubation of the same MHA and CaHA fractions after addition to the IRRI and Guimba soils. These two incubation soils had equally high levels of exchangeable $\mathrm{Ca}$, and, accordingly, the amount of $\mathrm{N}$ mineralization from added HA differed less between them than in this study between the IRRI and Tanhoi incubation soils. Specifically, after 6 wk aerobic incubation, MHA-N mineralization was on average only $8 \%$ greater in the Guimba soil than in the IRRI soil, and mineralization of CaHA-N was $36 \%$ less in the Guimba soil than in the IRRI soil (data not shown).

There was no evidence for any inhibition of microbial 
activity in the IRRI soil that would have slowed $\mathrm{N}$ mineralization from the amended HA. The amount of $\mathrm{N}$ mineralization in the unamended control soils was $30 \%$ higher in the IRRI soil than in the Tanhoi soil during the first $3 \mathrm{wk}$, and it was similar in both soils from 3 to $6 \mathrm{wk}$, suggesting uninhibited microbial activity in the IRRI soil. Both soils had favorable $\mathrm{pH}$ values and SOM levels. Other soil properties that may promote stabilization of HA, such as clay and SOM, were also similar in both soils.

The experimental design of this study was not intended to quantify the contributions of the MHA and CaHA to whole soil $\mathrm{N}$ mineralization. In fact, rapid $\mathrm{N}$ mineralization during the 6-wk incubation of this study suggests that the incubation method did not simulate field conditions. After the 6-wk incubation, as much as $45 \%$ of the humic $\mathrm{N}$ had been mineralized, suggesting incomplete restabilization of the HA that was added to the incubation soils. By comparison, extractions of the MHA from an irrigated lowland rice field indicated net mineralization of only about $10 \%$ of the $\mathrm{N}$ contained in the MHA during the first $53 \mathrm{~d}$ of a rice cropping period (Olk and Cassman, 2002). Nevertheless, the results of this study, in conjunction with those of Nguyen et al. (2004), indicate that these HA fractions are significant contributors to $\mathrm{N}$ mineralization of whole soil as measured using the anaerobic incubation procedure, and that the rate of $\mathrm{N}$ mineralization from these HA fractions depends on their chemical composition, which in turn is influenced by recent field management and soil moisture regime.

\section{ACKNOWLEDGMENTS}

This work was conducted during the authors' tenure at the International Rice Research Institute, and we are grateful for the support given by this Institute. Completion of this work was partially supported by funds from the USDA-ARS and the Hatch Act provided through the University of Nebraska Agricultural Research Division, Lincoln, NE. The authors also thank Achim Dobermann for help with statistical analyses and Marianne Samson for outstanding technical support.

\section{REFERENCES}

Baldock, J.A., and J.O. Skjemstad. 2000. Role of the soil matrix and minerals in protecting natural organic materials against biological attack. Org. Geochem. 31:697-710.

Bending, G.D., and D.J. Read. 1996. Nitrogen mobilization from protein-polyphenol complex by ericoid and ectomycorrhizal fungi. Soil Biol. Biochem. 28:1603-1612.

Burge, W.D., and F.E. Broadbent. 1961. Fixation of ammonia by organic soils. Soil Sci. Soc. Am. Proc. 25:199-204.

Cassman, K.G., S.K. De Datta, D.C. Olk, J.M. Alcantara, M.I. Samson, J.P. Descalsota, and M.A. Dizon. 1995. Yield decline and the nitrogen economy of long-term experiments on continuous, irrigated rice systems in the tropics. p. 181-222. In R. Lal and B.A. Stewart (ed.) Soil management: Experimental basis for sustainability and environmental quality. Lewis/CRC Publishers, Boca Raton, FL.

Chen, Y., N. Senesi, and M. Schnitzer. 1977. Information provided on humic substances by $\mathrm{E}_{4} / \mathrm{E}_{6}$ ratios. Soil Sci. Soc. Am. J. 41:352-358.

Christensen, B.T. 1992. Physical fractionation of soil and organic matter in primary particle size and density separates. Adv. Agron. 20:1-90.

Feller, C., and M.H. Beare. 1997. Physical control of soil organic matter dynamics in the tropics. Geoderma 79:69-116.

Kempers, A.J., and A. Zweers. 1986. Ammonium determination in soil extracts by the salicylate method. Commun. Soil Sci. Plant Anal. 17:715-723.

Knicker, H., S. Saggar, R. Bäumler, P.D. McIntosh, and I. KögelKnabner. 2000. Soil organic matter transformations induced by Hieracium pilosella $\mathrm{L}$. in tussock grassland of New Zealand. Biol. Fertil. Soils 32:194-201.

Kononova, M.M. 1961. The natural factors of humus formation. p. 203-230. In Soil organic matter: Its nature, its role in soil formation and in soil fertility. Pergamon Press, New York.

Kumada, K. 1987. Chemistry of soil organic matter. Japan Scientific Societies Press, Tokyo.

Mahieu, N., D.C. Olk, and E.W. Randall. 2002. Multinuclear magnetic resonance analysis of two humic acid fractions from lowland rice soils. J. Environ. Qual. 31:421-430.

Nguyen, V.B., D.C. Olk, and K.G. Cassman. 2004. Characterization of humic acid fractions improves estimates of nitrogen mineralization kinetics for lowland rice soils. Soil Sci. Soc. Am. J. 68:1266-1277 (this issue).

Olk, D.C., and K.G. Cassman. 2002. The role of organic matter quality in nitrogen cycling and yield trends in intensively cropped paddy soils. p. 1355-1-1355-8. In Proceedings, 17th World Congress of Soil Science. 14-21 Aug. 2002, Bangkok, Thailand. International Union of Soil Sciences.

Olk, D.C., K.G. Cassman, and T.W.M. Fan. 1995. Characterization of two humic acid fractions from a calcareous vermiculitic soil: Implications for the humification process. Geoderma 65:195-208.

Olk, D.C., K.G. Cassman, N. Mahieu, and E.W. Randall. 1998. Conserved chemical properties of young humic acid fractions in tropical lowland soil under intensive irrigated rice cropping. Eur. J. Soil Sci. 49:337-349.

Olk, D.C., K.G. Cassman, E.W. Randall, P. Kinchesh, L.J. Sanger, and J.M. Anderson. 1996. Changes in chemical properties of organic matter with intensified rice cropping in tropical lowland soil. Eur. J. Soil Sci. 47:293-303.

SAS Institute. 1990. The REG procedure. p. 1351-1456. In SAS/ STAT user's guide. Statistics. Ver. 6. 4th ed. Vol. 2. SAS Institute, Cary, NC.

Schimel, J.P., and M.K. Firestone. 1989. Inorganic N incorporation by coniferous forest floor material. Soil Biol. Biochem. 21:41-46.

Schnitzer, M., and M. Lévesque. 1979. Electron spin resonance as a guide to the degree of humification of peats. Soil Sci. 127:140-145.

Stevenson, F.J., and M.A. Cole. 1999. The internal cycle of nitrogen in soil. p. 191-229. In Cycles of soil: Carbon, nitrogen, phosphorus, sulfur, micronutrients. John Wiley \& Sons, New York.

Whalen, J.K., P.J. Bottomley, and D.D. Myrold. 2000. Carbon and nitrogen mineralization from light- and heavy-fraction additions to soil. Soil Biol. Biochem. 32:1345-1352.

Witt, C., K.G. Cassman, D.C. Olk, U. Biker, S.P. Liboon, M.I. Samson, and J.C.G. Ottow. 2000. Crop rotation and residue management effects on carbon sequestration, nitrogen cycling, and productivity of irrigated rice systems. Plant Soil 263-278.

Zech, W., N. Senesi, G. Guggenberger, K. Kaiser, J. Lehmann, T.M. Miano, A. Miltner, and G. Schroth. 1997. Factors controlling humification and mineralization of soil organic matter in the tropics. Geoderma 79:117-161. 